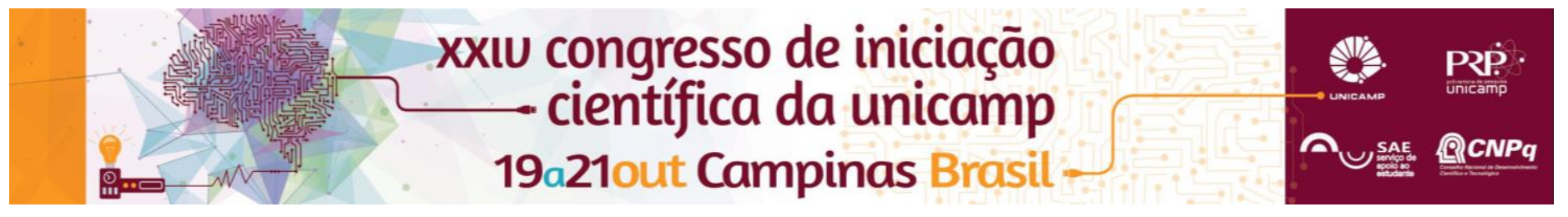

\title{
TENSÕES INDUZIDAS POR OVERDENTURES MANDIBULARES SUPORTADA POR UM IMPLANTE: ESTUDO FOTOELÁSTICO DO EFEITO DA ALTURA DO REBORDO RESIDUAL QUANDO SUBMETIDO AO CARREGAMENTO OCLUSAL
}

\author{
Tatiane Marinho*, Rafael L. X. Consani, Julia T. Campana
}

\begin{abstract}
Resumo
O objetivo neste estudo foi avaliar por meio da fotoelasticidade as tensões induzidas por overdentures suportada por um implante em rebordos residuais com diferentes alturas, quando submetidas à carga axial promovida pela prótese total maxilar convencional muco-suportada em oclusão. A prótese total convencional muco-suportada foi confeccionada de acordo com o recomendado pela Área Prótese Total da FOP/UNICAMP. A base foi de resina acrílica QC-20 e os dentes relacionados em articulador semi-ajustável. A prótese mandibular convencional deu origem às overdentures com um implante, com o objetivo de padronizar o relacionamento oclusal das próteses. As overdentures com diferentes alturas de rebordo alveolar residual são com implantes com superfície de $4 \mathrm{~mm}$ de diâmetro por $10 \mathrm{~mm}$ de comprimento e sistemas de anexos com diâmetros e comprimentos de 3,85 e $4,1 \mathrm{~mm}$, respectivamente. Os modelos fotoelásticos construído com resina Araldite foram submetidos à carga axial promovida pela prótese total superior convencional em oclusão com as overdentures. As tensões induzidas foram analisadas no modelo fotoelástico utilizando polariscópio circular e as imagens obtidas com filmadora digital. As tensões serão analisadas quantitativamente avaliando a intensidade e número de franjas mostradas pelo modelo fotoelástico.
\end{abstract}

\section{Palavras-chave \\ Prótese total, overdentures, tensões induzidas, fotoelasticidade.}

\section{Introdução}

Existem conceitos básicos para o tratamento da mandíbula desdentada com prótese suportada por dois a quatro implantes colocados na porção anterior do rebordo. São alegadas também diferentes vantagens $e$ desvantagens em cada tratamento; entretanto, tem sido sugerido a confecção de overdentures com um implante na região inter-forame de mandíbulas com acentuada reabsorção, situação que impossibilitaria a instalação de dois ou mais implantes em região mais distal (Schneider \& Synan, 2011). Atualmente existem relatos sugerindo que um implante seria adequado para reter overdentures e pode resultar em sucesso quando comparada às apoiadas por vários implantes (Cordioli et al., 1997; Glick \& Macentee, 2008; Wolfart et al., 2008). Este método de tratamento vem sendo indicado pela redução do custo e em situações com menor quantidade óssea quando comparada às reabilitações com maior número de implantes (Liddelow, 2007). Além disso, estudos recentes têm mostrado que overdentures com um implante podem alcançar resultados clínicos similares àqueles com maior número de implantes (Cordioli, 2007; Walton, 2009).

\section{Resultados e Discussão}

A altura do rebordo foi estabelecida no modelo de acordo com a classificação: Classe I (16 a $20 \mathrm{~mm}$ ); Classe II (11 a $15 \mathrm{~mm}$ ) ou Classe III (menor ou igual a $10 \mathrm{~mm}$ ). A confecção das próteses foi seguindo o critério tradicional e nas overdentures foram utilizados implantes hexágonos externo com conexão o'ring. Os modelos foram submetidos a carga axial promovida pela prótese total superior convencional em oclusão. Foi confeccionada uma prótese total superior convencional mucossuportada e foram confeccionadas três overdentures com 1 implante, todas com base de resina acrílica QC-20.
Os implantes são com superfície de 4,1 mm de diâmetro por $10 \mathrm{~mm}$ de comprimento e os sistemas anexos com diâmetros e comprimentos de $3,85 \mathrm{~mm}$. Foram confeccionados três modelos mandibulares de gesso tipo IV (Durone), a partir de um modelo anatômico inicial obtido de manequim desdentado (MOM). Foi confeccionada uma prótese total convencional que deu origem as overdentures. Foram confeccionadas bases de prova em resina acrílica (Vipi) e planos de orientação em cera, para que fossem relacionados em articulador semiajustável (A7 Plus; Bioart). Foi utilizado o plano de Camper para montagem do modelo superior no articulador, utilizando como referência as guias nas respectivas médias (ângulo de Bennett em 15 graus, guia condilar em 30 graus e pino incisal em zero grau).

Após a montagem dos modelos em articulador, os dentes artificiais (Ivoclar) foram posicionados nos planos de orientação de cera relacionados entre si no articulador. Foram instalados análogos dos implantes ao invés das fixações originais por não se tratar ainda do modelo definitivo em resina fotoelástica. Sobre os três modelos das overdentures confeccionados em gesso especial foram feitas moldagens para obtenção de moldes em silicone laboratorial (Zetalabor). Nesses moldes foi vertida a resina fotoelástica Araldite (componentes: Gy-279 BR e o endurecedor HY 2964).

\section{Conclusões}

Espera-se que os resultados deste estudo in vitro possam amenizar a intensidade das reabsorções ocorridas na região peri-implante.

\section{Agradecimentos}

Ao CNPq/UNICAMP/PIBIC pela concessão da bolsa de Iniciação Científica. 